\title{
Een explorerend kwalitatief onderzoek naar het leren consultvoeren door huisartsen in opleiding
}

\author{
A.M. Meijerink, P.M. Boendermaker, S. Bolhuis, J. Pols
}

\section{Samenvatting}

Inleiding: Bij medische vervolgopleidingen staat het leren op de werkplek centraal. Er is nog weinig bekend over de manier waarop assistenten in opleiding tot specialist (aios) op de werkplek leren hun werkzaamheden uit te voeren. Bij de huisartsopleiding in Groningen is daarom onderzoek gedaan naar de leervormen die aios gebruiken bij het leren consultvoeren, hoe deze samenhangen en welke rol werk en flankerend onderwijs hierin spelen.

Methode: Semi-gestructureerde diepte-interviews bij aios huisartsgeneeskunde die geanalyseerd zijn volgens een Grounded Theory benadering. Een initiële codeset werd ontleend aan een samenvatting van de leertheorieën rond leren door volwassenen en aan de opbouw van de opleiding.

Resultaten: Het blijkt dat bij het consultvoeren alle leervormen onder de koepel 'Leren door sociale interactie' zijn onder te brengen. Binnen die koepel ervaren aios vier leervormen: 1) leren door te doen, 2) model- of observatieleren, 3) leren door verwerking van theorie en 4) leren door reflectie.

Bij het leren consultvoeren fungeren 'leren door reflectie' en 'leren door te doen' als vliegwiel. Via reflectie drijven 'model- of observatieleren' en 'leren door verwerking van theorie' het vliegwiel aan. Flankerend onderwijs grijpt direct of indirect (via 2 en 3) aan op het leren door reflectie en het werk leidt direct tot leren door reflectie.

Conclusie en beschouwing: Het onderzoek levert een empirisch gefundeerd model voor leren consultvoeren door aios huisartsgeneeskunde. Het resultaat is praktisch bruikbaar, maar geeft ook aanleiding tot verder onderzoek. (Meijerink AM, Boendermaker PM, Bolhuis $S$, Pols J. Een explorerend kwalitatief onderzoek naar het leren consultvoeren door huisartsen in opleiding. Tijdschrift voor Medisch Onderwijs 2008;27(1):5-13.)

\section{Inleiding}

Tijdens vervolgopleidingen ontwikkelen assistenten in opleiding tot specialist (aios) zich tot zelfstandige beroepsbeoefenaren. Ruim 90\% van hun opleidingstijd besteden ze aan de patiëntenzorg. ${ }^{1}$ Dit deel van hun opleiding voldoet aan alle kenmerken die Onstenk noemt voor 'leren op de werkplek': 1) het doel is het verwerven van een beroepsgericht handelingsrepertoire (competenties) waarbij 2) de situaties uit de beroepspraktijk het leerobject vormen en 3 ) de reële arbeidssituatie de leeromgeving is. Onstenk defi- nieert leren op de werkplek als: “... een individuele, constructieve activiteit waarmee de lerende/werkende een praktisch relevant (arbeids)probleem in de vingers probeert te krijgen, als gevolg waarvan een uitbreiding plaatsvindt van het duurzame handelingsrepertoire ...". ${ }^{2}$ Leren op de werkplek wordt gestuurd door het werk (inhoud, verloop en structurering van de arbeidsactiviteit), de sociale werkomgeving (collega's, andere medewerkers), de lerende zelf en de begeleiding/coaching op de werkplek door opleiders en supervisoren. Leren op de 
werkplek heeft daardoor een sterk informeel karakter. ${ }^{3-4}$

Naast het leren op de werkplek hebben vervolgopleidingen nog twee goed van elkaar te onderscheiden onderdelen. In de eerste plaats de onderwijsactiviteiten zoals vaardigheidstrainingen, rollenspelen, casusbesprekingen, refereerbijeenkomsten, zelfstudie, vakliteratuur en symposia. In het hoger beroepsonderwijs noemt men dit geheel van activiteiten steeds vaker 'flankerend onderwijs', een term die we ook in dit artikel hanteren. Het laatste onderdeel van de vervolgopleidingen is het toetsprogramma.

Eén van de drijfveren achter de huidige modernisering van de vervolgopleidingen is dat ze doelgerichter en doelmatiger moeten worden. ${ }^{5}$ Met het oog daarop is het nuttig om een goed beeld te hebben van de wijze waarop aios leren op de werkplek en hoe het flankerend onderwijs dit leren faciliteert. Die kennis kan helpen bij het ontwikkelen van doelgerichte curricula die de groei van aios tot zelfstandige beroepsbeoefenaren zo goed mogelijk ondersteunen. Over het leren op de werkplek van aios en de relatie met flankerend onderwijs is echter weinig bekend. ${ }^{3}$

Bij de huisartsopleiding is altijd veel aandacht besteed aan de didactiek tijdens het werk in de patiëntenzorg en de wisselwerking met het flankerend onderwijs. ${ }^{6-7}$ De opleiding heeft een duale leeromgeving: elke opleidingsweek bestaat uit vier werkdagen en één 'terugkomdag' (tkd) met flankerend onderwijs. ${ }^{6}$ Het flankerend onderwijs bestaat uit uitwisseling van ervaringen, scholing in medisch inhoudelijke onderwerpen, training van (consultvoerings)vaardigheden en attitudevorming. ${ }^{6}$

In het eerste en derde jaar van de driejarige opleiding werken aios mee in een huisartspraktijk. In deze Huisartsen LeerWerkPeriode (hlwp) voeren ze alle werk- zaamheden uit die in een huisartspraktijk voorkomen, zoals consulten, visites, diensten en samenwerken met assistente, praktijkverpleegkundigen, specialisten en andere hulpverleners. Het tweede opleidingsjaar is de Externe LeerWerkPeriode (elwp) buiten de huisartspraktijk. Afhankelijk van eerder opgedane ervaring en belangstelling volgen aios dan stages in verpleeghuizen, instellingen voor geestelijke gezondheidszorg en op poliklinieken en afdelingen van ziekenhuizen.

Hoewel de huisartsopleiding goed doordacht en in de loop der jaren steeds beter gefundeerd is, 68 is geen onderzoek gedaan naar de leervormen die bij aios een rol spelen. Daar in de huisartsopleiding het leren consultvoeren centraal staat, is daar nu onderzoek naar gedaan om een antwoord te krijgen op de volgende drie vragen:

- Welke leervormen gebruiken aios huisartsgeneeskunde bij het leren consultvoeren?

- Hoe hangen die leervormen samen?

- Wat is de rol van werk en flankerend onderwijs hierbij?

\section{Methode}

Daar nog weinig bekend is over de leervormen die aios gebruiken en leren een deels onzichtbare activiteit is, is gekozen voor het verzamelen van data met behulp van semi-gestructureerde interviews waarin aios zelf aan het woord komen. ${ }^{9}$ De interviews zijn afgenomen bij de aios huisartsgeneeskunde van de Huisartsopleiding Groningen. Bij het selecteren van gesprekspartners is gestreefd naar een zo groot mogelijke spreiding over de opleidingsjaren. ${ }^{10}$

Voor de analyse van de data is gekozen voor een Grounded Theory benadering met als doel te komen tot een modelbeschrijving van gebruikte leervormen en hun relatie met flankerend onderwijs. ${ }^{10-11}$ Voor leervormen bestaat een grote hoe- 
veelheid begrippen die samenhangen met verschillende visies op leren. ${ }^{12}$ Omdat het onderzoek zich concentreerde op het gebruik van leervormen in de praktijk en niet op het vinden van nieuwe leervormen, is dit begrippenkader genomen als startpunt bij de analyse. Met deze werkwijze sluiten we aan bij een lange traditie onder de meer liberale gebruikers van de Grounded Theory. ${ }^{13}$

\section{Uitvoering en analyse van interviews}

Bij de interviews was de openingsvraag steeds: "Je zit nu in het ... jaar van je opleiding. Hoe heb jij tot nu toe geleerd consulten te voeren?" Op geleide van het antwoord is doorgevraagd. Met behulp van een topiclijst is in de loop van de interviews dieper ingegaan op de verschillende leervormen en hun relatie tot het werk in de patiëntenzorg en flankerend onderwijs. ${ }^{14}$ Het verzamelen van zoveel mogelijk verschillende uitspraken over het leren consultvoeren, heeft geleid tot de ontwikkeling van een zeer rijk beeld daarvan. ${ }^{15}$ Het afnemen van interviews en het analyseren wisselden elkaar af in een iteratief proces. ${ }^{13}$ In elk volgend interview is het accent gelegd op nog bestaande lacunes in de dekking van werk- en onderwijssituaties en zijn vragen gesteld die ontstonden naar aanleiding van de analyse van eerder afgenomen interviews.

De interviews zijn letterlijk uitgetypt en ingevoerd in Atlas-ti, een softwarepakket dat administratieve ondersteuning biedt bij kwalitatief onderzoek. ${ }^{16}$ Met het afnemen en analyseren van interviews is doorgegaan tot verzadiging werd bereikt: er werden geen nieuwe feiten meer gevonden. ${ }^{10} 15$

\section{Ontwikkeling codeset}

Voor de codering van leervormen is uitgegaan van bestaande begrippen. ${ }^{13} \mathrm{In}$ een samenvatting daarvan onderscheidt
Bolhuis vier overlappende leervormen: ${ }^{12}$

1. leren door directe ervaring, waarbinnen het leren door te doen en het leren door meemaken (model- of observatieleren) worden onderscheiden,

2. leren door sociale interactie van individuen,

3. leren door verwerking van theorie en

4. leren door reflectie in de zin van: nadenken over of (her-)interpreteren van eigen of andermans handelen.

Voor de codering van werk en flankerend onderwijs is de opbouw en invulling van de huisartsopleiding gevolgd. In twee proefinterviews is de codeset op bruikbaarheid en volledigheid getest. Voor de codes rond werk en flankerend onderwijs was dat het geval.

Van de leervormen bleek sociale interactie (2) niet als aparte onderscheidende categorie te kunnen worden afgezonderd. Van sociale interactie is steeds sprake bij leren door directe ervaring (1) en bij leren door reflectie (4), bijvoorbeeld in contact met patiënten en in gesprekken met de huisartsopleider. Ook leren door verwerken van theorie (3) vatten we op als - indirecte - sociale interactie met auteurs die op het moment van bestuderen niet aanwezig zijn. In navolging van recente sociaal-culturele interpretaties van leren, beschouwen we sociale interactie in dit onderzoek daarom als koepel voor de vier andere leervormen. ${ }^{3}$

Om de intersubjectiviteit van de codes vast te stellen, zijn ze door twee onderzoekers onafhankelijk van elkaar gebruikt bij het coderen van een blanco versie van de twee proefinterviews. De coderingsverschillen tussen beide onderzoekers bleken te berusten op vergissingen of over het hoofd zien van gespreksfragmenten. De intersubjectiviteit van de gebruikte codes is dus groot. Tabel 1 vat de ontwikkeling van de codeset samen. 
Tabel 1. Ontwikkeling codeset.

\begin{tabular}{|c|c|c|}
\hline Codeset & Vóór proefinterviews & Na proefinterviews \\
\hline \multirow[t]{2}{*}{ Leervormen } & & $\begin{array}{l}\text { Leren door sociale interactie } \\
\text { met vier leervormen: }\end{array}$ \\
\hline & $\begin{array}{l}\text { - Leren door directe ervaring, } \\
\text { waarbinnen leren door te doen en } \\
\text { leren door meemaken (model- of } \\
\text { observatieleren) worden onderscheiden } \\
\text { - Leren door sociale interactie } \\
\text { - Leren door verwerking van theorie } \\
\text { - Leren door reflectie }\end{array}$ & $\begin{array}{l}\text { - Leren door verwerking van theorie } \\
\text { - Leren door reflectie }\end{array}$ \\
\hline Werk en & 'Terugkomdag' (tkd) & 'Terugkomdag' (tkd) \\
\hline flankerend & Huisartsen LeerWerkPeriode (hlwp) & Huisartsen LeerWerkPeriode (hlwp) \\
\hline onderwijs & Externe LeerWerkPeriode (elwp) & Externe LeerWerkPeriode (elwp) \\
\hline
\end{tabular}

\section{Resultaten}

Binnen het tijdsbestek van het onderzoek zijn acht interviews van gemiddeld een uur afgenomen bij twee eerstejaars, drie tweedejaars en drie derdejaars aios.

De zeven ontwikkelde codes zijn in de loop van het onderzoek verder verfijnd. Daarbij zijn subcategorieën ontstaan, bijvoorbeeld voor de diverse onderwijsvormen op de 'terugkomdagen', maar er bleken geen nieuwe codecategorieën nodig te zijn. Aios huisartsgeneeskunde blijken de leervormen die uit de proefinterviews naar voren kwamen ook in de praktijk te ervaren en noemen geen aanvullende leervormen. Op dit punt is dus verzadiging van informatie bereikt.

\section{Model}

Aios ervaren in het leren consultvoeren een vliegwiel van de leervormen 'reflecteren' en 'doen' (figuur 1). Model- of observatieleren en leren door verwerking van theorie leiden pas via de tussenstap van reflecteren tot doen. Alle curriculumonderdelen hebben een relatie met één van de vier leervormen en dragen zo bij aan het op gang houden van het vliegwiel. Ter illustratie van dit proces een citaat:

'Je tipt elkaar, als je een bandje van elkaar hebt gezien. (...)(M) Iemand heeft bijvoorbeeld een hele mooie openingszin en dat je dan denkt (R) van "Hé, die kan ik ook wel eens een keer gaan doen $(\boldsymbol{D})$...'

Hieronder geven we eerst een weergave van het model dat het eindresultaat van het onderzoek vormt. De vier verschillende leervormen en hun samenhang met de onderdelen van het curriculum komen daarna gedetailleerder aan bod. De resultaten van de analyse worden samengevat en waar dat relevant of illustratief is, onderbouwd met citaten uit de interviews.

\section{Leren door te doen}

Als zij zelfstandig een consult voeren ervaren aios 'leren door te doen'.

'Je leert een consult door het te doen, door het veel te doen!' 


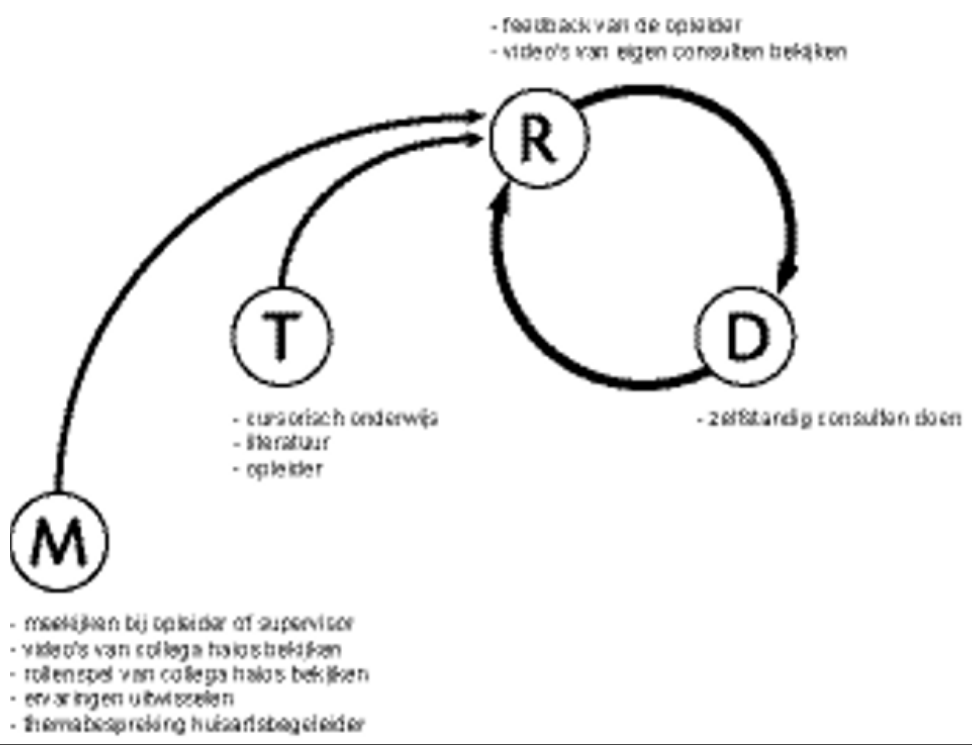

Figuur 1. Model van de manier waarop aios huisartsgeneeskunde het leren consultvoeren ervaren: een vliegwiel van doen $(D)$ en reflecteren $(R)$ waarbij reflecteren ook wordt aangedreven door model- of observatieleren $(M)$ en leren door verwerking van theorie $(T)$.

De aio leert, door zelf het consult te voeren, in de interactie met de patiënt wat goed werkt en wat niet.

'... Je doet iets en dat blijkt een goede uitwerking te hebben, dus dat ga je vaker doen en er gaat iets fout (...) en dat doe je dan minder vaak.'

Wanneer de aio zelfstandig een consult voert, kan dit tot reflectie leiden. Dit moment van reflectie kan zowel tijdens (reflection-in-action) als na (reflection-on-action) het doen van het consult optreden. ${ }^{17}$

'Soms dan merk je van: "Hé, nu ben ik de hulpvraag van mijn patiënt aan het invullen." (...) Dan denk je op een gegeven moment van: "Dit wil de patiënt helemaal niet." En dan moet je toch weer terug.'

'(...) dan denk je pas na het consult van oh dat ging niet goed.'

\section{Model- of observatieleren}

Bij het model- of observatieleren dienen vier verschillende personen als model voor de aios: huisarts-opleider, collega aios, huisarts(groeps)begeleider en de supervisor in de externe leerwerkperiode. De aio ziet (eventueel op video) of hoort van hen hoe een consult gevoerd kan worden. Andere didactische werkvormen die tot deze leervorm leiden, zijn het uitwisselen van ervaringen, themabesprekingen van de huisarts(groeps)begeleider en het bekijken van rollenspelen van collega aios.

'De opleider waar ik het eerste jaar mee heb samen gewerkt, daar zag ik wel eens consulten bij. (...) Hij gebruikte bepaalde woorden waarvan je dacht van "Ja, dat is heel handig."'

'Een voorbeeld is een van de huisartsbegeleiders hier. (...). Zij had een hele mooie zin om goed aan te sluiten bij deze patiënt.' 
Het uitwisselen van ervaringen over hun werk door de aios tijdens de 'terugkomdag' vindt zowel gepland (ervaringsronde) als ongepland (bijvoorbeeld tijdens de lunchpauze) plaats.

\section{‘...) Dat spuien vindt georganiseerd binnen} zo'n groep plaats, maar ook als je elkaar een half uurtje eerder treft of in de lunchpauze of waar dan ook. Dan worden er gewoon ervaringen uitgewisseld en daar zitten genoeg ervaringen bij waarvan je denkt van: "Verrek dat maak ik ook heel veel mee." En daarna praat je erover van goh wat moet je ermee. Moet je het veranderen, kun je het anders doen. Daar steek je zeker wat van op.'

Ook het bekijken van elkaars consulten op video is een didactische werkvorm die tot model- of observatieleren leidt.

'Dat zie je terug als je video's van elkaar bekijkt (...). Dan zie je ten eerste hoe je collega aios huisartsgeneeskunde het doen. Ik zie dingen waarvan ik denk: "Dit is een goede opmerking, of een goede timing, of een hele mooie open vraag." En ik zie ook dingen die ik perse niet wil doen.'

\section{Leren door verwerking van theorie}

Aios melden drie bronnen van theorie te gebruiken bij het leren consultvoeren: onderwijs, literatuur en de huisartsopleider. Tijdens de 'terugkomdag' volgt de aio cursorisch onderwijs over verschillende onderwerpen. Deze didactische werkvorm is een input voor leren door verwerking van theorie.

'Soms is het iets wat je hier hebt geleerd op de 'terugkomdag' met een lastige patiënt. Dat je denkt van: "Dat zal ik een keer toepassen de volgende keer."'

'Tijdens de 'terugkomdagen' is er ruimschoots de tijd voor consultvoering. (...)
Dus dan krijg je allerlei modellen en trainingen op verschillende manieren. (...).'

Maar ook lezen van literatuur en vragen stellen aan de opleider dragen er aan bij.

'Ik denk dat ik vier of vijf boekjes gelezen heb die over consultvoeren gingen (...).'

'In het eerste jaar vraag je de achtergronden van bijvoorbeeld een medicijn aan je opleider.'

\section{Leren door reflectie}

Reflectie neemt volgens aios een centrale plek in bij het leren consultvoeren (figuur 1). Reflectie treedt niet vanzelf op. Er is altijd een aanleiding die ervoor zorgt dat de aio gaat reflecteren op zijn eigen of andermans handelen. De aanleiding kan rechtstreeks zijn via een didactische werkvorm, bijvoorbeeld door het kijken naar een video van zichzelf. De aio ziet op de video hoe hij of hoe een collega aio een consult voert en dit leidt vervolgens tot reflectie.

'(...) je ziet jezelf en je hoort jezelf en dan kom je soms achter van hé doe ik het zo.'

Ook het feedback krijgen van anderen leidt rechtstreeks tot reflectie. De aio huisartsgeneeskunde krijgt van zijn collega aios, huisartsbegeleider, gedragswetenschapper en huisarts-opleider feedback op zijn consultvoering. Deze feedback leidt bij de aio tot reflectie.

'(...) dan denk je van: "Dit was een goed consult." Dan hoor je van: "Ja maar ho ho, dit ging niet goed of dat niet." En denk je: "Hé, daar zeg je me wat!"'

Maar reflectie kan ook geïnitieerd worden door één van de andere drie leervormen. 


\section{Conclusie en beschouwing}

Het onderzoek levert een empirisch gefundeerd model voor de samenhang tussen leervormen die aios huisartsgeneeskunde gebruiken bij het leren consultvoeren en de rol van werk en flankerend onderwijs daarbij (zie figuur 1). De drie onderzoeksvragen uit de inleiding zijn als volgt te beantwoorden:

1. Het leren consultvoeren van aios huisartsgeneeskunde is te karakteriseren als leren door sociale interactie en niet zozeer als individuele activiteit, zoals Onstenk vermeldt. ${ }^{2}$ Aios ervaren vier leervormen: leren door te doen, modelof observatieleren, leren door verwerking van theorie en leren door reflectie.

2. De kern van het leren consultvoeren zoals aios huisartsgeneeskunde dat ervaren - bestaat uit het vliegwiel van reflecteren en doen. Model- of observatieleren en leren door verwerking van theorie leiden via reflecteren tot doen.

3. De vier leervormen komen tot stand door werk en flankerend onderwijs. Flankerend onderwijs leidt direct tot leren door reflecteren of doet dat via de tussenstap van model- of observatieleren en leren door verwerking van theorie. Het werk zelf leidt direct tot leren door reflectie. Samen met het flankerend onderwijs zorgt het werk voor het op gang houden van het vliegwiel van reflectie en doen.

Acht interviews vormen een stevige basis voor de onderlinge relatie tussen de vier leervormen. De laatste interviews leverden daarover geen nieuwe gegevens meer op en hier is verzadiging bereikt. ${ }^{10}$ Verzadiging werd niet bereikt voor de relatie van het flankerend onderwijs met de vier leervormen, de manier waarop werk en flankerend onderwijs zich tot elkaar verhouden en de mate waarin zij bijdragen aan het leren consultvoeren. Om van het huidige model naar een theorie over leren consultvoeren te komen, is meer onderzoek noodzakelijk. ${ }^{13}$

Een andere kanttekening betreft de generaliseerbaarheid van het model. Hoewel de kern een generieke indruk maakt, is over de feitelijke generaliseerbaarheid naar andere taken en andere opleidingen niets bekend. Daar staat tegenover dat het daadwerkelijk werkzaam zijn in de patiëntenzorg deel uitmaakt van elke vervolgopleiding. Het ligt daarom voor de hand dat het vliegwiel voor het leren van aios steeds zal bestaan uit leren door reflectie en leren door te doen. Dat daarnaast ook de andere twee leervormen steeds voorkomen, lijkt aannemelijk. Wel mogen grote verschillen verwacht worden in de mate waarin werk en flankerend onderwijs bij andere opleidingen bijdragen aan het leren consultvoeren. De huisartsopleiding en de overige opleidingen verschillen immers sterk van elkaar met betrekking tot inhoud en opbouw van het flankerend onderwijs en de didactische inbedding van het werken in de patiëntenzorg. ${ }^{1,6}$ Tegenover deze kanttekeningen staat dat de kern van het model direct praktisch bruikbaar is in alle vervolgopleidingen. Die kunnen nagaan of de werkzaamheden van de aio en het flankerend onderwijs optimaal worden benut om het vliegwiel van het leren - de cyclus van reflectie en doen - aan te drijven.

\section{Aanbevelingen}

Dit onderzoek werd gedaan als bijdrage aan het zichtbaar maken van de doelgerichtheid en doelmatigheid van vervolgopleidingen op het gebied van het leren consultvoeren. Om die zichtbaarheid te vergroten verdient het aanbeveling om de figuur uit dit onderzoek verder te ontwikkelen tot een theorie rond het leren consultvoeren. Ook andere taken kunnen daarbij worden betrokken. Daarvoor is o.a. onderzoek nodig dat: 
- impliciete vormen van leren in beeld brengt,

- de rol van het flankerend onderwijs verder preciseert,

- verduidelijkt wat de relatieve bijdragen aan het leren zijn van werk en flankerend onderwijs.

Om tot resultaten te komen met een generiek karakter zal daarbij ook onderzoek gedaan moeten worden in andere vervolgopleidingen.

\section{Literatuur}

1. Heineman, E. Voordracht tijdens de presentatie van het eerste bestuur van het College voor de Beroepen en Opleidingen in de Gezondheidzorg (CBOG), 27 februari 2007. http://www.medischevervolgopleidingen.nl/pages/content/S2/nieuws56 .aspx [Bezocht op 10-5-2007].

2. Onstenk JHAM. Lerend leren werken: brede vakbekwaamheid en de integratie van leren, werken en innoveren. [proefschrift] Delft: Eburon; 1997.

3. Swanwick T. Informal learning in postgraduate medical education: from cognitivism to 'culturism'. Medical Education 2005;39(8):859-65.

4. Eraut M, Boulay B du. Developing the attributes of medical judgement and competence. University Sussex: Institute of Education; 2000.

5. Bleker OP, Hoorntje JCA, Schelfhout VJ. Beter en leuker: CCMS ontvouwt plannen voor de vervolgopleiding van medisch specialisten. Med Contact 2004;59(43):1692-5.

6. Anonymus. Project Vernieuwing Huisartsopleiding. http://www.svuh.nl/. [Bezocht op 3-7-2007].

7. Berkestijn L van. Ontwikkelingen in de huisartsopleiding. Huisarts Wet 2003;12(46):672-5.

8. Kramer AWM. Acquisition of clinical competence during postgraduate training in general practice. [proefschrift] Universiteit Maastricht; 2003.

9. Baarda DB, Goede MPM de, Teunissen J. Basisboek kwalitatief onderzoek: praktische handleiding voor het opzetten en uitvoeren van kwalitatief onderzoek. 2 dr. Groningen: Stenfert Kroese; 2005.

10. Strauss AL, Corbin JM. Basics of qualitative research. Techniques and procedures for developing grounded theory. 2 dr. Thousand Oaks: Sage; 1998.

11. Hsieh HF, Shannon SE. Three approaches to qualitative content analysis. Qual.Health Res. 2005;15(9):1277-88.

12. Bolhuis $\mathrm{S}$. Leren en veranderen bij volwassenen, een nieuwe benadering. 2 dr. Bussum: Uitgeverij Coutinho b.v.; 2001.

\section{Dankwoord}

Zonder de hulp van de aios huisartsgeneeskunde zou dit onderzoek niet plaats hebben kunnen vinden. Daarnaast zijn de auteurs dank verschuldigd aan drs. G.G. Toren (universitair docent Andragogiek, Rijksuniversiteit Groningen) voor zijn suggesties bij de opzet en uitvoering van het onderzoek.

13. Kennedy TJT, Lingard LA. Making sense of grounded theory in medical education. Med Educ 2006;40(2):101-8.

14. Hulshof M. Leren interviewen: het mondeling verzamelen van informatie. Groningen: WoltersNoordhoff; 1992.

15. Wester F. Strategieën voor kwalitatief onderzoek. derde dr. Bussum: Coutinho, 1995.

16. Muhr T. ATLAS/ti - A Prototype for the Support of Text Interpretation. Qualitative Sociology 1991;14(4):349-71.

17. Schön DA. The reflective practitioner. How professionals think in action. Aldershot Arena: Ashgate Publishing Limited; 1983.

De auteurs:

Mw. drs. A.M. Meijerink is kwaliteitsmedewerker, Zorggroep Oude en Nieuwe Land, Steenwijk.

Dr. P.M. Boendermaker is huisarts en senior stafmedewerker, Wenckebach Instituut, Universitair Medisch Centrum Groningen.

$M w d r . S$. Bolhuis is onderwijskundige, Onderwijsinstituut, Universitair Medisch Centrum St Radboud, Nijmegen en lector, Fontys Lerarenopleiding, Tilburg.

Dr. J. Pols is arts-onderwijskundige, Wenckebach Ontwikkelplatform, Universitair Medisch Centrum Groningen.

Correspondentieadres:

Dr. J. Pols, Wenckebach Ontwikkelplatform, Universitair Medisch Centrum Groningen, postbus 30.001, 9700 RB, Groningen. Tel.: 050-3611609;

email: j.pols@wenckebach.umcg.nl

Belangenconflict: geen gemeld.

Financiële ondersteuning: geen gemeld. 


\section{Summary}

Introduction: Workplace learning is a central feature of postgraduate medical education but little is known about how trainees learn to perform tasks and activities. In the general practice training programme of Groningen University Medical Center, we investigated: (1) different approaches used by trainees in learning consultation skills, (2) the relationship between these different approaches and (3) the roles of work and of formal education in this.

Method: We performed and analysed semi-structured in depth interviews with general practice trainees and used a grounded theory approach for the content analysis. We derived an initial set of codes from a review of theories of adult learning and from the training programme.

Results: Learning through social interaction is the overarching concept in learning how to conduct a consultation. Trainees use four learning strategies: (1) learning by doing, (2) modelling or observational learning, (3) learning by processing theory and (4) learning by reflection.

The acquisition of consultation skills is driven by learning by doing and by learning by reflection. Mediated by reflection, modelling or observational learning and learning by processing theory are the driving forces of the learning process. Formal training is directly or indirectly related to learning by reflection (via 2 or 3), whilst working leads directly to learning by reflection.

Conclusion: It proved possible to develop an empirical model of how general practice trainees acquire consultation skills. This model is of practical importance but at the same time raises further research questions. (Meijerink AM, Boendermaker PM, Bolhuis S, Pols J. A qualitative exploratory study of how general practice trainees acquire consultation skills. Dutch Journal of Medical Education 2008;27(1):5-13.) 